\title{
Developing a New Scalable SaaS e-Business Solution with Ticket Manage- ment
}

\author{
Marjan Gusev, Sasko Ristov \\ University Ss Cyril and Methodius, FCSE \\ Rugjer Boshkovic 16 \\ Skopje, Macedonia
}

\author{
Kristina Kolic \\ Haybrooke Associates \\ 10 Pelham Street, \\ Leicester, LE2 4DJ, UK
}

\begin{abstract}
Modern SMEs (Small and Medium Enterprises) target solutions with electronic automated processes and administration. They would rather use integrated software solutions offered as a service instead of employing specialised staff or administering their own software. In this paper we address E-Business solutions that integrate offers, orders, invoices, and payments.

The proposed e-Business solution is based on ticket management features to administer defined process states on the way reaching the final state in the sales and business processes customised for a $S M E$. Here we present life cycles for the processes of ordering, offering, invoicing and payment and give details on SaaS implementation. The offered solution includes a scalable architecture implemented as a cloud SaaS.
\end{abstract}

\section{Introduction}

The pace of changing the activities within a small or medium enterprise (SME) is really fast. This constant change requires adjusting strategy, includes new technologies and may cause challenges or conflicts in the working under the new conditions. However, the economic efficiency of the business can be determined by the information presented through the accounting system. A problem appears when the accounting system cannot accommodate the SME needs. The reason for this is the complexity of the accounting system, the investing in a new infrastructure whenever a change is on the way, and dedicating most of the staff for different purpose and their time to work with the system. The SMEs cannot afford financially either the system or the personnel to achieve this goal and make a change. The affordable solution is service in the cloud which can be accessed from everywhere and doesn't require a huge investment in the software and infrastructure [1].

The most valuable information for one SME is the answers to the following questions: 'Is there any order?', 'Was an invoice generated for the order and sent to the customer?', 'Was the invoice paid once I have the daily bank statements?' and 'Was the ordered product/service delivered to the customer?'. All these answers are provided by the e-Business information system which has accounting module which might be too complex for the users. If the complexity of that module is the same as the ticket management system, the information will be easily accessible, more understandable and limited to just what the SME needs.

Some of the companies still decide to outsource the processes that are non-core activities of the business. This sometimes leads to duplication of the effort and high costs for the process [2]. The solution presented has the ability to put back the financial processes inside e-Business solution in a simple way and cut the expenses for the outsourcing.

A research to prove the thesis 'Does e-Business matter to SMEs?' was conducted for over $1500 \mathrm{Eu}-$ ropean, American and Canadian SMEs. The main reason why the e-Business solutions are widely accepted is the reported significant financial benefits. During the period of using an e-Business solution, the SMEs had revenue growth and cost minimisation [3].

The paper is organized as follows. Section 2 is allocated for describing the characteristics and processes of the information systems for SMEs dealing with e-Business, while Section 3 will be focused on the properties of the ticket management system. The model of the new system, presented as integration between the e-Business information system and the ticket management system, will be demonstrated in Section 4. Section 5 presents the lifecycle of the documents, represented as tickets, used in the processes used in the finances of an e-Business solution with integrated ticket management system. The scalable architecture of the system is described in Section 6. The advantages of using the new system will be discussed in Section 7, while Section 8 is reserved for the conclusion and future work.

\section{Information systems for e-Business}

A formal definition of the accounting information systems (AIS) is the following: An AIS is a collection of data and processing procedures that creates needed information for its users [4]. The AISs perform tasks which cover areas from the financial accounting, managerial accounting and taxation (e.g. 
payroll, accounts receivable and payable, inventory etc). Also, they are capable of generating reports on which base the most of the company strategic planning is done.

Not only the processes from the accounting are involved in the AISs. More and more often, these systems are tools used by other departments of a company, such as sales, marketing, production or human resources department. The data that is processed give very valuable information for the decision-makers and the stakeholders of the company.

Parts of the financial accounting cycle are the journals, ledgers, the trial balances and financial statements and also the coding system. They are all used in the recording of the transactions and the business events. The journals can be described as lists where all the business events are logged chronologically. Examples of journals are sales journals, purchase journals, cash receipts journals etc. A ledger is a collection that has all the financial information about the company's assets, liabilities, revenues and expenses. Once the transactions are in a journal and in the ledger, the trial balance is adjusted, and it represents a list of all the accounts and their debit and credit balances. The financial statements include income statements, balance sheet, and cash flow statement as well. Usually each accounting system depends on a coding system. The coding system contains predefined codes for every action in the system, so the system can record, store, order and get the data.

Each AIS is composed of three major subsystems:

- Transaction processing system - This system deals with the everyday business operations which are supported by numerous documents and reports.

- General ledger/financial reporting system The subsystem provides the traditional financial statements (income statement, balance sheet, statement of cash flow, tax returns etc.) required by law.

- Management reporting system - All the reports and information needed for company decision making for budgets, marketing etc., are produced through this subsystem [5].

The AIS covers all the finance, accounting and audit processes in a company. It is usually used by the companies that are large enterprises and which have a big accounting or finance departments.

Nowadays, the Internet and mobile technologies have changed the way one business works and how the finances in the company are led. Each business, no matter the size, offers the products/services through web applications to their customers, which means starting to behave as an e-Business. That is why the e-Business is defined as an online exchange of value. The e-Business solution supports the main processes and operations in the company, and helps the employees and management in making decisions
[6]. Above all, the e-Business solution must have a small part of the AIS in order to take record of every offer, order, invoice and payment in the system. Mainly, only some features of the mentioned subsystems are in use: transactions which follow the sales process with some reports that may initiate the decision making process. This way, some of the internal finance processes will be mapped into the e-Business solution. The e-Business solution is affordable for the SMEs and doesn't require as much resources, technology or human, as the AIS.

There are two stages that a company will pass through on the way of the implementation of eBusiness. The first stage involves adoption of e-mail as a communication method, implementing LAN for file-sharing and also adoption of solution for data back-up. This phase is lower cost and every SME is able to archive it. The second stage consists of establishing the web presence of the company as 'flat ad site', 'brochure website' or maybe 'e-commerce' solution. This phase requires many changes, including restructuring the supply chains, reconfiguration of the business-customer relationship, and as well the restructuring the processes within the company. As additional changes to this phase might appear the adoption of new working practices with partners, allowing remote access to the employees, transformation of the marketing and sales, and introduction of new financial management practices [7].

One of the crucial process for an e-Business information system is the sales process. The company revenues come from sale of the goods and services that the company offers. The start event in the sales process includes offering products or services from which offer the customer picks the desired product and places an order. From this point, there are two possible scenarios. The first one is that the order triggers the billing process, which starts with the generation of an invoice which is due to be paid by some date. When the customer pays the due amount, the payment is processed and the good has to be delivered. The second scenario includes a process for advanced payment after the order, so that the company is sure that the customer will pay for the product, and that the same time the billing process starts and also the delivery of the product. Each company decides what the suitable way of processing the order is.

All the data that is input is part of some output reports such as the financial statements, cash receipts forecast, customer listing or management reports. Other reports can be also output of the sales process, for example customer billing statement, which summarises all the invoices and the amount that the customer owes, the ageing report, which shows the balance of the revenue in categories, or the bad debt report which contains information for the overdue for each customer. 
Another important process is the purchasing process, which starts with request for good from the company' side and ends with payment to the vendor of that good. The company has need to buy something, so the request turns into an order. After that, the company receives a purchase invoice (vendor's sales invoice). Then the payment is done to the vendor. The company's accounting system has to follow the whole process and as output to generate reports (financial statements, vendor listing, and management reports).

In large companies, where production and financing (checks, investments, lending etc) processes take place, the AIS can take care of those processes [4]. In SMEs, many factors do not allow the usage of the AIS, but the introduction of the e-Business model can bring automation of the finance processes needed for sale. This paper will present an e-Business solution intended for the SMEs.

\section{Ticket management systems}

Ticket management systems are also known as issue tracking systems or specifically as bug reporting systems. The ticket management system is answer to the problem of tracking the issues that appears during the development and testing phase of a software project. In a team of a number of developers it is hard to keep track of the assigned tasks and found bugs and their status. Usually, when a system is not available, the best way for tracking was big lists for each worker, or many posts sticked on board or working desk. With usage of system this is no longer a problem because everything is centralised and reachable by everyone. The issues (tickets) are tracked by the means of the progress indicator which can be presented as per cent or different states of the progress to the solution e.g. new, in progress, resolved etc. [8].

The ticket management system main feature is to manage the issue life cycle. The lifecycle represents the issue transition from one state to another while processing, beginning with the start state and ending with the final state. Each change in the states of the lifecycle has a meaning and is important to one or more users in the system, so they are notified whenever the issue changes the state. This represents another important feature of the ticket management system, system notification for each state transition of the lifecycle to the relevant users. The notifications can be done by sending an email, a text message (sms) or shown whenever the user logs in in the system. This feature is also known as alerting or reporting.

However, often the word 'issue' can be misunderstood. The word issue doesn't represent a problem or bug, but also a task that has to be done. The main feature of the system is to track those issues. Every type of issue has different properties, depending on its nature, but all together they have the same properties which include fields for assigned to, date of assignment, comments, notes etc. [9]. Issue can stand for bugs and defects but also for feature requests, work orders, support requests, or documents [10]. This information is needed in order to have a complete reported issue: reporter, importance, severity (if it is a bug), component and reporting date and time [11].

The most popular issue-tracking systems are the following: Bugzilla, Redmine, Collaboa, Trac, Lighthouse, Eventum, WebIssues, Fossil etc. Some of them are open source and free to use solutions, and some of them are commercial [10][12].

\section{Specification of a new hybrid system}

This section presents the results from our earlier paper [13] as an integration of ticket management system into an e-Business information system for SMEs. Additionally, we present how these two systems can exist and communicate together.

\subsection{Description}

The purpose of this section is to describe the new combined system and its overall architecture.

Many of the processes in the e-Business information system, as described in Section 2, have the subprocess of putting an issue in a different state. The different states make the lifecycle of the issue.

The main feature of the ticket management system can be noticed here: tracking the ticket through the phases/states of its processing. The same feature can be recognised in the processes of offering, receiving and processing customers' orders, invoicing and allocation of the payments by the means of the bank statements. According to this, many types of issues or tickets can be recognised in the new system.

The issues are linked between each other. This means that in a state of progress of an issue, another type of issue is generated and put in the first state of progress. On the other hand, an issue state can trigger change of states of another issue. It can be said that the system has chained and complex lifecycle issues. These lifecycle issues are created upon the business rules of the parts of an AIS that are used in the eBusiness system.

For entering into each individual state the system must realise alerting, for example by sending an email notification to the user who is in due for that issue type in that certain state and if the issue state allows customer transparency then also the customer should be notified for the state change. 


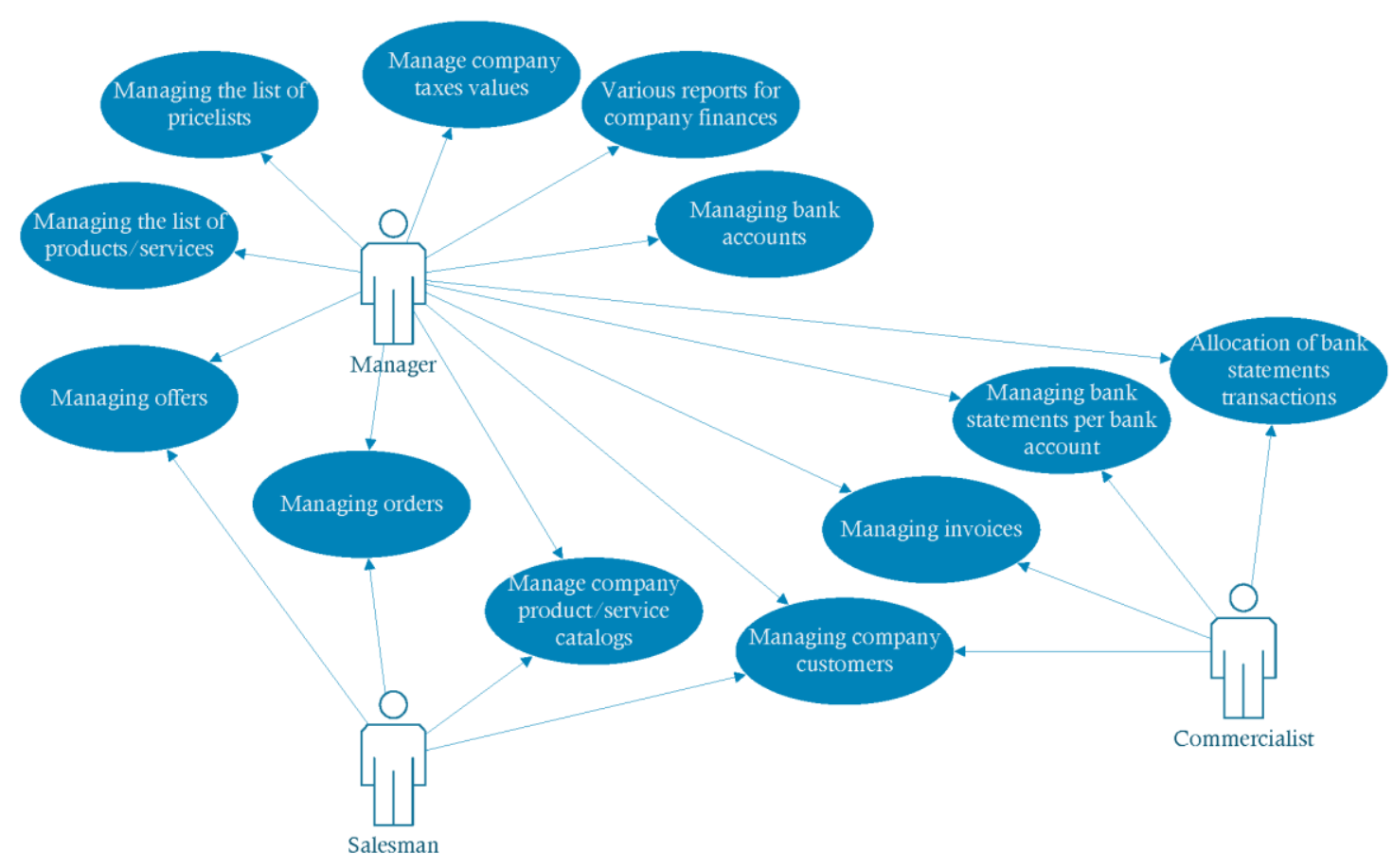

Fig. 1 Use case diagram

\subsection{Features}

The features of the new system are based on upgrading some of the features of the e-Business information system with the lifecycle behaviour that the tickets in the ticket management system have.

Most of the features found in the finance module of an e-Business solution are also present in eProcurement solution. An e-Procurement system is based on profiles, and some of them are grouped into the standards CEN/BII, PEPPOL and EBizz4All [14][15].

The purpose of the profiles is to facilitate the public procurement solution. The concepts of e-ordering and e-invoicing are introduced in the e-Procurement solution. Some of the basic profiles that the model uses are: new basic order, order response, new basic order using catalog, new basic invoice, invoice dispute, revoke invoice and revoke order. These profiles are further used in more complex profiles: advanced ordering without catalog, advanced invoicing, procurement without catalog and procurement using catalog.

All these profiles combined give us the same features needed, and as separated may be equated to the states of the tickets used in the new system.

Besides all the other user roles which are directly linked to the e-Business system nature, the users of the new e-Business system management module are organised in the following roles:

- Manager role - The manager has access to the features that require overall control and management, such as browsing a list of is- sues, (e.g. products, price-lists, fulfilled orders, sent invoices, outstanding payments).

- Salesman role - The salesman role integrates several functions (such as marketing, ordering and delivery) and is responsible for the features that cover the sales process, which includes management of the offers and orders.

- Commercialist role - The administrative employee that realises the commerce features has the ability to control the finalisation of the sales processes in the system, such as invoicing and payments.

All the roles have access to the different types of issues in their different progress states. Some of the roles can have access to the same issues but in different states.

We will take a closer look at the features in the part of the sales processes and the finance module of the e-Business system (Fig. 1). Here the integration of the two systems is visible the most:

- Managing the list of products/services - This feature enables the manager of the company e-Business system to manage the products or services that the company offers. All the products can be divided into categories for easier managing.

- Managing the list of price-lists - The manager is responsible for the price-lists that are used for the products/services. At a time, only one price-list can be active, but the manager can also schedule different price-list to be active at some period of time. 
- Manage company product/service catalogs The catalogs are representative material of the company products/services. This feature is available to the manager and the salesman.

- Manage company taxes values - This feature enables the manager to set the taxes that are used for different categories of products/services according to the company home country laws for taxes.

- Managing company customers - All the user roles can access and manage the list of the company customers. The customers can be other companies or individuals. They will be present in every of the documents in the features described below. It is important that all the finance can be filtered also by customer, so the company is aware of the payments of the customers' companies/individuals.

- Managing offers - The manager and the salesman users have access to the creating and managing the existing offers. When an offer is created, the system requires the customer for which the offer is meant, and also the products to be offered. The offers might be put in different states during the processing.

- Managing orders - The orders are documents based on the offers, or just simply on a purchase of certain products/services. They are based per customer and a product or a group of products. This feature is available to the salesman and the manager. The orders initiate the generating of the invoices. The orders pass through several states which will be described in the next section.

- Managing invoices - The manager and the commercialist have access to the list of created invoices, and the creating invoices feature as well. The invoices are documents that are created manually when the customer orders a product/services offline, or they are generated by the system having the data of a certain order. These invoices are called outgoing invoices. There is also another type of invoices that the company receives from other companies for purchased goods. Those are the incoming invoices. Each invoice contains the information about the customer, product(s)/service(s) ordered, and the total price requested for the sold product(s)/service(s). The orders have few states, which will be described in the next sections.

- Managing bank accounts - The manager has control over the accounts that the company posses. A company is able to have more than one account in different currencies, e.g. one account in home currency and other in the main foreign currency used in the country.
The bank accounts are needed to manipulate with the bank statements and allocation.

- Managing bank statements per bank account - The manager and the commercialist have access to the management of the bank statements per each company bank account. This feature enables to manually input the bank statements of the bank account per day, or import the daily bank statement from xml file provided by the bank.

- Allocation of bank statements transactions This feature serves the purpose of allocating the bank statements transactions with issued invoices to the customers. This way, the commercialist or the manager knows if the customer paid for the provided product/service. The feature has automatic and manual mode. If the invoice reference and the bank statement transaction reference are the same, the bank statement transaction will be allocated to that invoice. If it is not possible to allocate the transaction, the commercialist or the manager has to allocate the transaction manually, by choosing the appropriate invoice. The tickets management feature for states will be used for the bank statements transactions too.

- Various reports for company finances - The manager of the company is able to see a number of reports about the company finances. They cover the reports for the transactions per customer for a period of time, company expenses, or company customers that cause the biggest debt. Based on those, the company business intelligence reports are created, which can be used for company further actions.

As we can see the manager has access all the feature, but there are also two other roles that have access to a subset of the features. This organization of the roles is made so that if the SME has the resources then it can allocate them in all the roles, or just keep the access from a manager user if the SME can't allow staff for all the roles.

\section{Tickets lifecycle}

The lifecycle of offers, orders, invoice and processing of bank statements for the new proposed system is presented next according to our earlier paper [13].

\subsection{Offers}

The sales process starts by offering the goods or services to the customers. An offer is an official company document, which serves for that purpose. A marketing agent from the company, which tries to 
sell, uses the offer to explain the product/service to be sold, the terms of use and propose a price. Once the offer is sent, the customer can accept or decline the offer.

Each offer contains information for the product/service, the price and terms. It is valid for customer acceptance for a defined period of time. If a company has a predefined price list for the product/services offered, the offer for a customer is usually a promotional mix proposal, direct marketing, or personal selling.

From this, we can see that the offer passes through three out of four possible states. When it is created, the offer is in state 'New'. When the offer is sent by email to the customer, it will enter the state 'Sent'. Now it depends on the customer if the offer will be in state 'Accepted' or 'Declined'. The offer must be in only one of the states 'Accepted' or 'Declined' at a time.

The final state of this process initiates repetition of the whole offer process if 'Declined' or generating the order when 'Accepted'.

The state diagram of the lifecycle of the offers is shown in the Fig. 2.

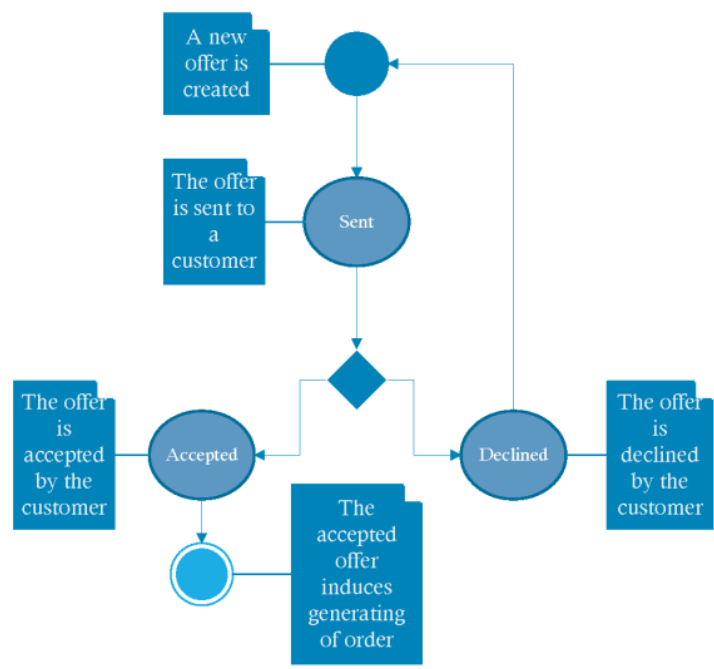

Fig. 2 Lifecycle of an offer

\subsection{Orders}

The order is a document that is generated once the customer decides to accept an offer for a product or service or to buy a product. This suggests that the orders do not always succeed the offers. It also passes through several states before ending its life cycle and by that it provides the employees of the company with the information of its status.

Once the order is generated in the system, it is in the state 'Accepted' which shows the customer that their order is already with the company provider of the products/services. When the order is opened by any of the authorized employees, it will go in the state 'Executing'. This means that the employee starts to process the order of the customer, e.g. packing the products needed, or schedule a service to start. When the product/service is delivered to the customer, the order is in state 'Delivered', which is followed shortly with the state 'Generated invoice'. It depends on the company's policies when the document for payment, an invoice, should be generated and sent to the customer. When the time is right, the employee sends the invoice to the customer, so that the customer can pay for the products/services.

There is a state that the customer or the company employee can put the order in. It is the 'Cancelled' state, in which the order can be at any time, if the customer decides that the product/service is no longer wanted.

The Fig. 3 represents state diagram of the lifecycle of an order in the system.

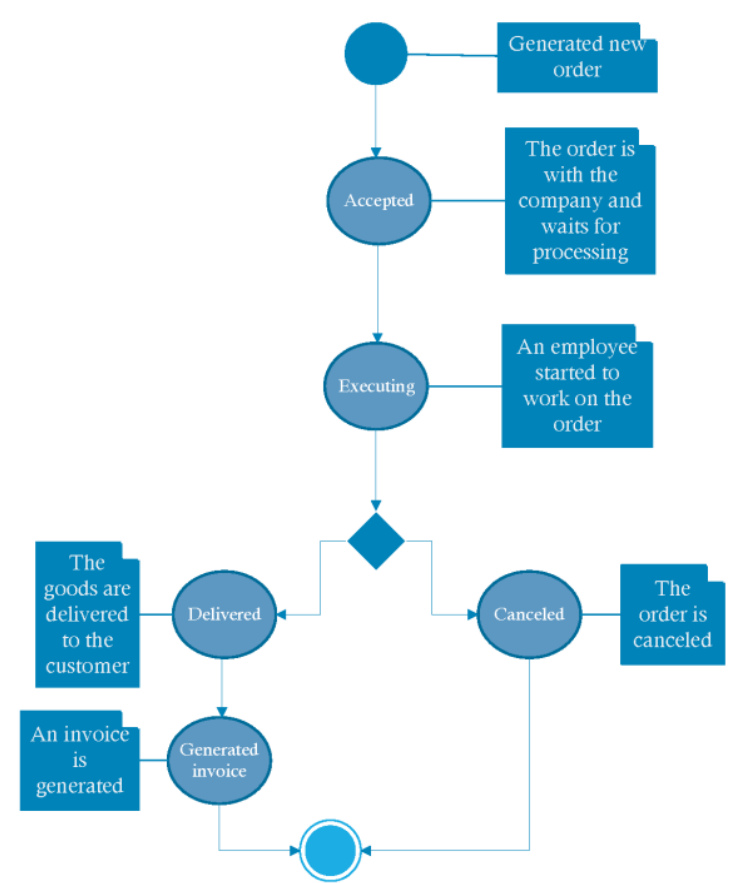

Fig. 3 Lifecycle of an order

\subsection{Invoices}

The invoices represent the 'bill' for the product/service that has to be paid from the customer. It can be generated shortly before the delivery or in some cases after the delivery was done. If the sales process happens outside the e-Business information system, the invoices must be created manually.

The invoice starts its lifecycle with the 'Working' state or the 'Issued' state. The 'Working' state shows that the company employee creates the invoice manually and that the invoice is not yet ready to be sent to the customer. The 'Issued' state is presenting the stage of the process when the invoice was ready and sent to the customer. If the invoice is being created manually, whenever the employee decides to 
send the invoice to the user it will change the state to 'Issued'. Once the customer pays the sum of money according to the invoice, the invoice is matched to a bank statement and goes into the state 'Paid'.

The similarity between the invoices and orders is in the presence of the state 'Cancelled' for the invoices too. The reason for this state existence is the same. The invoice is put in this state when the user no longer wants the product/service ordered.

The state diagram in the Fig. 4 presents the lifecycle of each invoice.

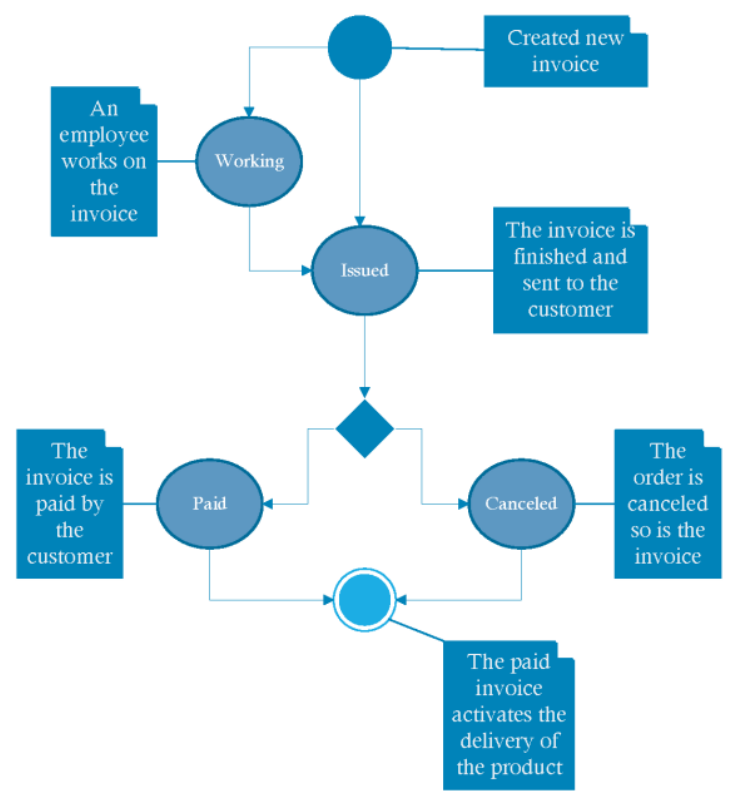

Fig. 4 Lifecycle of an invoice

\subsection{Bank statements}

The bank statements are documents that are generated each time a transaction happens in the bank account of one company. They have details for all the debit transactions that company made, and all the credit transactions that the customers made according to the sent invoices.

This element of the finances is different than the previously described ones. Each bank statement contains one or more transactions. Each creadit transaction can match payment made by invoice generated in the system, so there are states are per transactions of the bank statement and states per the bank statement itself. The bank statement states are based on the states of the credit transactions of the same bank statement.

There is a strong link between the invoices and the bank statements. One of the invoice states, 'Paid', is based on the status of one of the transactions of the bank statements.

When the bank statement is first imported in the system, all the transactions in it have the state 'Not allocated'. If all the transactions have the state 'Not allocated', then the bank statement state is 'Not allocated' too. Once one transaction is matched with an invoice by the amount of money required, the transaction status changes to 'Allocated'. If all of the transactions are in the 'Allocated' state, the bank statement goes to the 'Allocated' state.

The state diagram of the lifecycle of the bank statements is represented in Fig. 5.

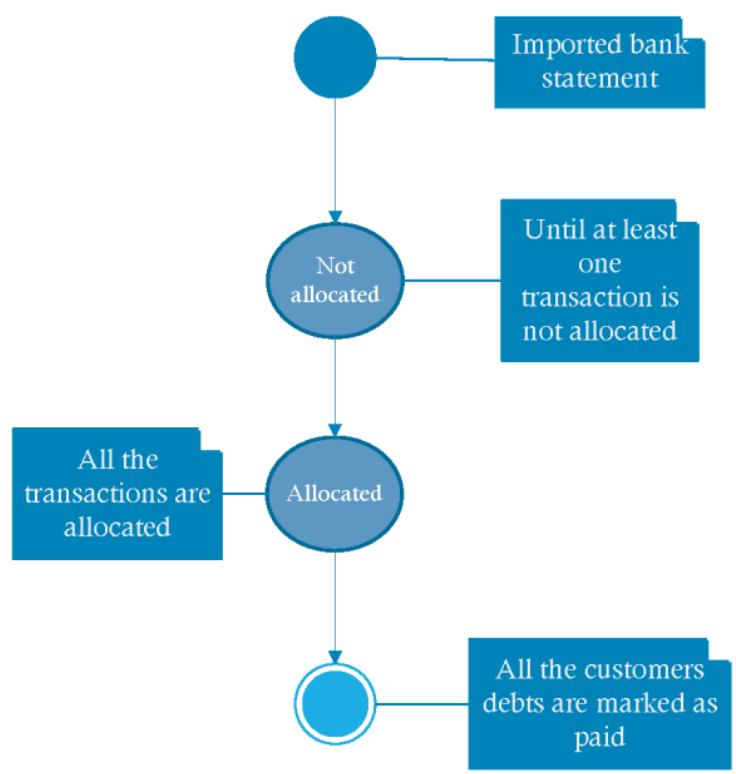

Fig. 5 Bank statement's lifecycle

\section{Specifying a scalable SaaS}

Kolic et al. [16] discuss advantages and benefits of a SaaS e-Business system. Here we present the architecture of such system.

Fig. 6 presents the three main modules (Management, Reporting and Accounting).

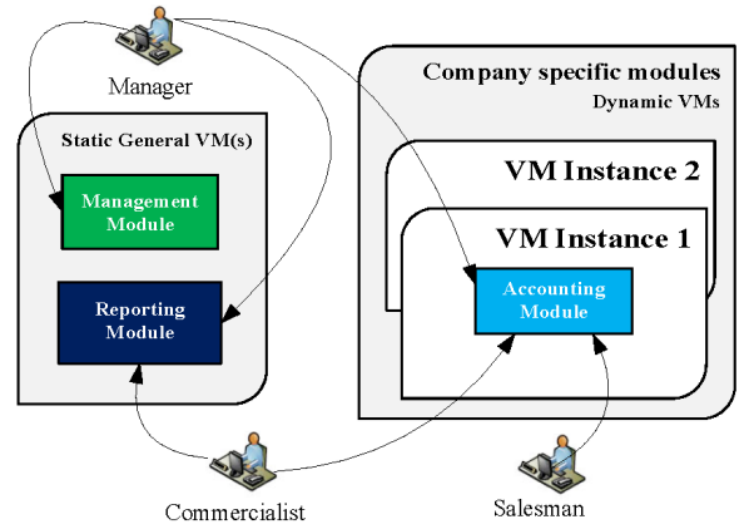

Fig. 6 Architecture of a scalable e-Business solution

These modules are organised as static and dynamic modules in a scalable solution. The idea is to separate the static (predictable) and dynamic (unpre- 
dictable) parts or modules and then to host the static part on the single virtual machine (or physical server), while the dynamically instantiated virtual machines in the cloud should be used to host accounting modules of one or several companies, depending of their requirements and size. This scalable architecture is based on the scalable e-Assessment cloud architecture defined by Ristov et al. [17].

Let us describe the architecture. Management module is defined as static since it depends on the number of customers, products, price lists, and so on, which are more or less predictable and static values. That is, increasing the number of customers is usually static and predictable (for example, $5 \%$ per year, or 10 per day, etc). Reporting module is also defined as static due to similar reasons.

Accounting module, on the other side, is unpredictable. That is, the number of created orders, invoices, payments and other accounting documents is unpredictable. Even more, the number of database accesses is increased since each document has a list of items. Additional increase of database accesses are updating or revoking some document.

This architecture offers additional performance improvement since the system will work with smaller databases per company, rather than having one huge database, even it is distributed. However, once there is a demand for increased processing power, a new virtual machine with corresponding modules will be activated.

Table 1 classifies all features of Fig. 1.

Table 1 Static and dynamic services

\begin{tabular}{|l|l|}
\hline \multicolumn{1}{|c|}{ Static } & \multicolumn{1}{|c|}{ Dinamyc } \\
\hline products/services & offers \\
price-lists & orders \\
product/service catalogs & invoices \\
taxes values & \\
customers & \\
bank accounts & \\
bank statements & \\
bank statements transac- & \\
tions & \\
reports & \\
\hline
\end{tabular}

\section{Discussion}

SMEs can obtain a number of advantages by the usage of the new hybrid system for e-Business purposes. First of them is the automation of the non computerised business information systems in a much easier way. The features taken from the ticket management system make the system understandable and enable the user to get familiar with the system in a very short time. That is because the ticket management systems are spread world wide and used in for any product/service related issue system, very well known by the ordinary users. The company costs for any training for the system usage will be minimal or none.

Another advantage is that at any moment the company will have evidence of the sent invoices, received payments or delivered products/services. This feature is useful when more than one person is responsible for any of the sales or commerce processes. Because the system is centralised, it contains all the relevant data, which avoids the why or who questions between the employees in the bigger organisations. It also reduces the number of employees due to automation processes enabled by the software solution of the ticket management features that offer alert notification and reporting.

The solution allows the company board chiefs to make their decisions for any further actions based on very precise data that the system offers in the reports.

The potential of using the cloud environment for the new system gives few advantages over the stand alone or server-client solutions. If available as software-as-service (SaaS), the system will be used as service for more than one company. The methods used for billing "pay-as-you-go" (fixed monthly/yearly fee) or "pay-by-the-drink" (monthly spent amount of a measure) are both attractive way of paying for the service, and very beneficial to SMEs. The company can start to use the SaaS straight away, without any additional installations or setup like the standalone or server-client solutions.

As a cloud solution, the system will also used the infrastructure-as-service (IaaS) provided by the cloud computing environment. This cloud-service model enables the usage of the physical hardware needed for running the system, and network between the servers as well. The data centres where the servers reside offer an environment for which a company doesn't have any obligation to administer. The cost for servers and network administration for the serverclient systems are often very high, and the companies usually spend a lot of time and resources for the administration.

The cloud computing environment also offer another benefit through the model platform-as-service (PaaS). This concept offers stable computing environment where the systems can be hosted. The computing environment in consisted of operating systems, database management systems and web server. The greatest benefit of this is that the company doesn't have to manage the installation of the platform, the software licences, the software updates, the disaster recovery and further maintenance of the platform.

Overall, the cloud solution is a perfect way to enlarge the scaling and elasticity properties of the solution. This environment provides plenty of resources which can be used depending on the system demands. In times when the system is overcrowded of concurrent users and needs more powerful resources, multiple virtual environments can be activated, so the solution works better. In that way, the 
system is more scalable and elastic which makes another advantage over the standalone and serverclient solutions.

Performance analysis of an SaaS ticket management system was realised by Gushev et al. [18]. We plan to explore if these conclusions about performance also hold for this kind of e-Business solution.

\section{Conclusion and future work}

The coherent solution obtained by implementing ticket management in the business information systems is presented in this paper. It offers an idea for an innovation, based on the already known features of the both systems, especially for SMEs.

This system might be further enhanced by extension to work as software as service (SaaS) in the cloud. That change will enable the system be accessible and used by more than one company at a time, reducing the overall administration costs.

The main challenge of representing the system as SaaS is the company accounts and users and the security of the data that is exposed to each user. This system requires special attention to the security because it works with the most sensitive company data, the finance data. Only certain number of employees are authorised to see and work with that data.

The benefits of the proposed system go towards automation of the financial processes needed for the functioning of one e-Business system. This means that the all the current paperwork will be replaced with this solution. The company will have prompt information about all the current documents and processes at every moment. The SaaS solution enables lower costs for installation, maintenance, and administration of a solution, and lower costs for hardware, infrastructure and network too.

Most of all, the new solution simplify the current solutions for e-Business with finance module. Because of its implemented features from the ticket management system, which is well known among ordinary users, it will allow users to get to know the system for short time, without any training.

The future work will involve developing this model of a system as SaaS. The system will reside in cloud environment and further analysis and experiments will be inducted so the mentioned benefits are confirmed.

\section{References}

[1] C. Christauskas and R. Miseviciene, "Cloudcomputing based accounting for small to medium sized business," Engineering Economics, vol. 23, no. 1, pp. 1421, 2012.
[2] M. L. Markus, "Paradigm shifts-e-business and business/systems integration," Communications of the Association for Information Systems, vol. 4, no. 1, p. 10, 2000.

[3] D. A. Johnston, M. Wade, and R. McClean, "Does ebusiness matter to SMEs? a comparison of the financial impacts of internet business solutions on European and North American SMEs," Journal of Small Business Management, vol. 45, no. 3, pp. 354-361, 2007.

[4] N. A. Bagranoff, M. G. Simkin, and C. S. Norman, Core Concepts of Accounting Information Systems. (11th edition). Wiley, John Wiley and Sons, 2010.

[5] J. Hall, Accounting information systems. Cengage Learning, 2012.

[6] J. A. O'Brien, Introduction to Information systems. McGraw-Hill, Inc., 2010.

[7] P. Windrum and P. De Berranger, The adoption of ebusiness technology by SMEs. MERIT, Maastricht Economic Research Institute on Innovation and Technology, 2002.

[8] M. Gusev, S. Ristov, and P. Gushev, "Developing a ticket management SaaS solution," MIPRO, 2014 Proceedings of the 37th International Convention, IEEE Conference Publications, Opatija, Croatia, pp. 322-327, 2014.

[9] C. Henderson, Building scalable web sites. O'Reilly Media, Inc., 2006.

[10] B. Ediger, Advanced Rails. O’Reilly Media, Inc., 2007.

[11] T. Zimmermann, R. Premraj, J. Sillito, and S. Breu, "Improving bug tracking systems," 31th International Conference on Software Engineering (ICSE Companion 2009), Vancouver, BC, Canada, 2009.

[12] P. Gushev, A. Guseva, S. Ristov, and M. Gusev, "Cloud solutions for bug reporting," XLVIII Int. Scientific Conference on Information, Communication and Energy Systems and Technologies (ICEST), pp. 227-230, 2013.

[13] K. Kolic, M. Gusev, and S. Ristov, "A new e-business solution with ticket management," in Information Society (i-Society), 2014 International Conference on, London, UK, 2014, pp. 203-208.

[14] Pan European Public Procurement On Line. (2014) Peppol home page. [Online]. Available: http://www.peppol.eu/

[15] K. Kiroski, M. Gusev, M. Kostoska, and S. Ristov, "Modifications and improvements on cen/bii profiles," in ICT Innovations 2011, ser. Advances in Intelligent and Soft Computing, L. Kocarev, Ed. Springer Berlin / Heidelberg, 2012, vol. 150, pp. 395-404.

[16] K. Kolic, S. Ristov, and M. Gusev, "A model of saas e-business solution," in Telecommunications Forum (TELFOR), 2014 22nd, Belgrade, Serbia, Nov 2014, pp. 11461149.

[17] S. Ristov, M. Gusev, G. Armenski, K. Bozinoski, and G. Velkoski, "Architecture and organization of eassessment cloud solution," in IEEE Global Engineering Education Conference (EDUCON), 2013 IEEE. Berlin, Germany: IEEE, Mar. 2013, pp. 736-743, best Paper Award.

[18] P. Gushev, S. Ristov, and M. Gusev, "Performance analysis of SaaS ticket management systems," in Computer Science and Information Systems (FedCSIS), 2014 Federated Conference on, Sept 2014, pp. 753-760. 